\title{
Endosonographically guided gallbladder drainage to treat neoplastic jaundice after Roux-en-Y gastric resection
}

A 81-year-old man, who had undergone subtotal gastric resection with Roux-en-Y anastomosis for gastric adenocarcinoma 2 years earlier, was admitted to our hospital for obstructive jaundice. Abdominal computed tomography showed a solid mass $(30 \times 30 \mathrm{~mm})$ at the pancreatic head, involving the common bile duct and the duodenum and suspicious for portal vein and mesenteric axis invasion ( Fig.1). An endoscopic ultrasonography (EUS)-guided fine needle aspiration was performed and a diagnosis of metastasis of gastric adenocarcinoma was made.

Considering the post-surgical anatomy, and in order to obtain endoscopic biliary drainage, a transgastric intrahepatic EUS-guided approach was attempted. A linear echoendoscope (GF-UCT140; Olympus, Tokyo, Japan) was used but the intrahepatic bile ducts were not dilated enough to access them. However the hydropic gallbladder was clearly visible from the jejunal route.

EUS-guided transluminal gallbladder drainage was therefore performed using a lumen-apposing metal stent (LAMS) (Hot Axios; Boston Scientific, Natick, Massachusetts, USA) with a lumen diameter of $10 \mathrm{~mm}$. The gallbladder was first punctured using a $19 \mathrm{G}$ access needle (EchoTip Ultra; Cook Medical, Limerick, Ireland) and a 0.035-inch guidewire (VisiGlide; Olympus) was left inside to stabilize the echoendoscope position. Subsequently the stent was introduced into the gallbladder lumen using its cautery tip. Finally the stent was deployed ( Fig.2), with subsequent rapid drainage of the gallbladder into the jejunal lumen ( $>$ Fig.3, and $\triangleright$ Video $\mathbf{1}$ ), and nasobiliary drainage was inserted through the stent into the lumen of the gallbladder ( $>$ Fig.4). The procedure was successful and the patient's jaundice rapidly resolved; after 2 weeks total bilirubin had fallen from $11.3 \mathrm{~g} / \mathrm{dL}$ to $2.5 \mathrm{~g} / \mathrm{dL}$ ).

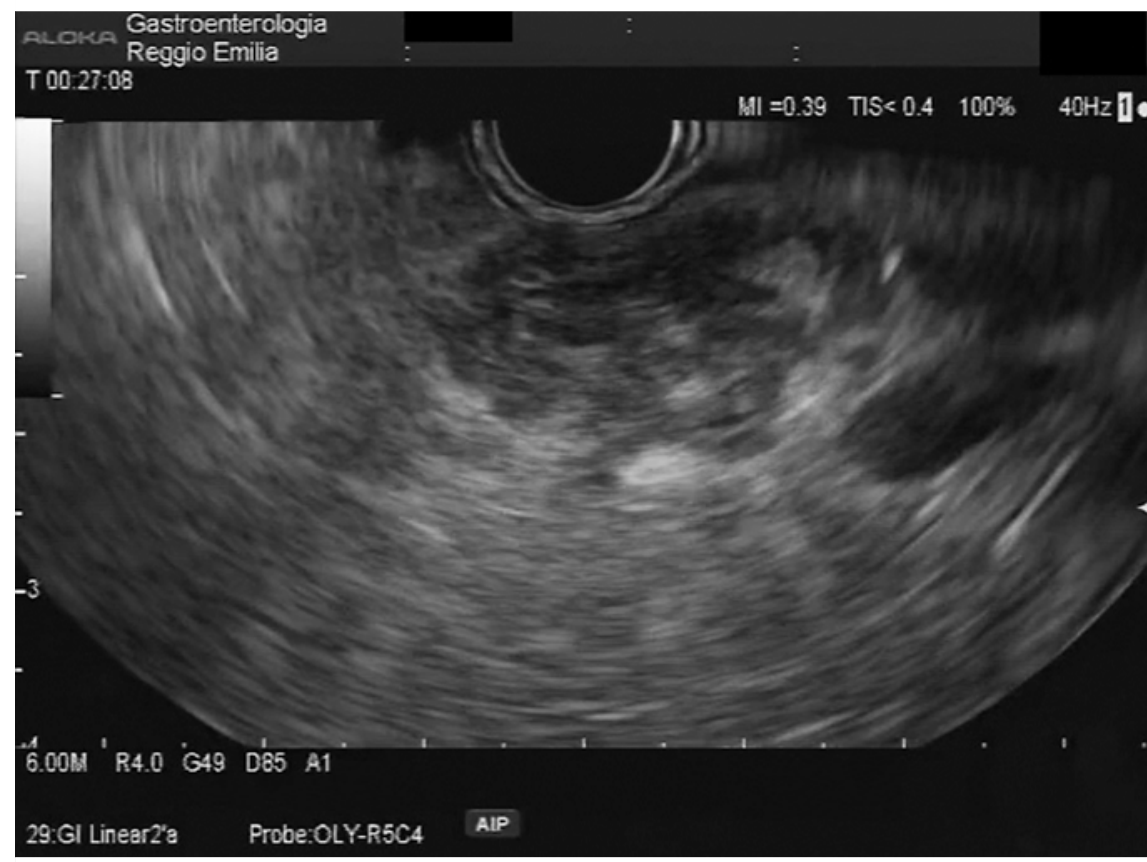

Fig. 1 Endoscopic ultrasound (EUS) view of pancreatic mass in an 81-year-old man treated 2 years previously for gastric adenocarcinoma by subtotal gastric resection with Roux-en-Y anastomosis.
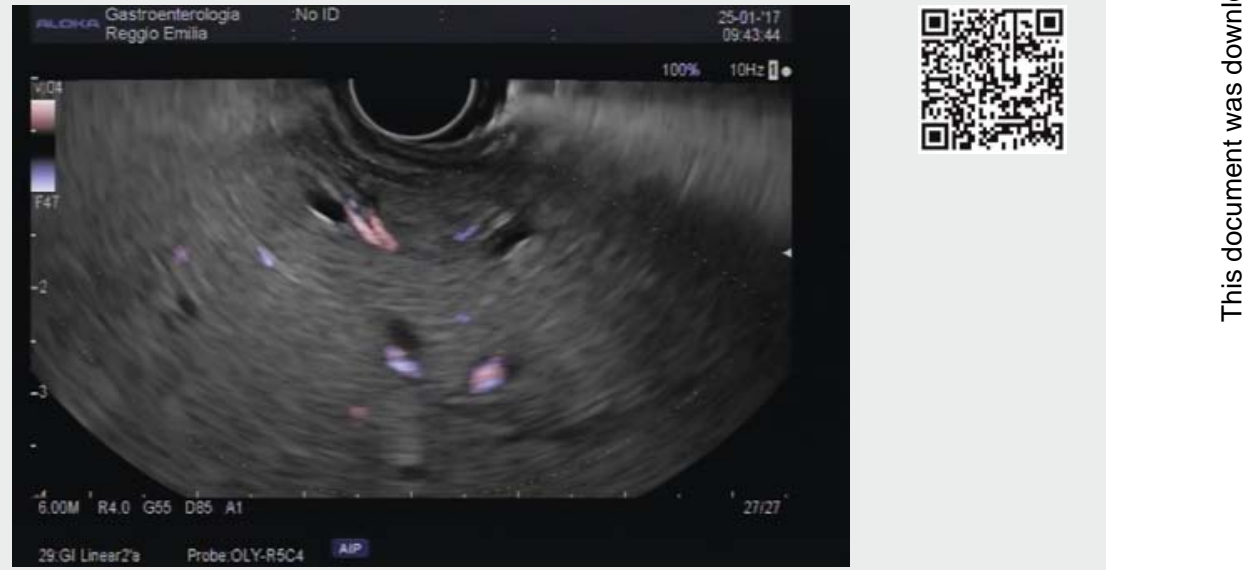

Video 1 Endoscopic ultrasound (EUS)-guided transluminal gallbladder drainage performed using a lumen-apposing metal stent (LAMS). 


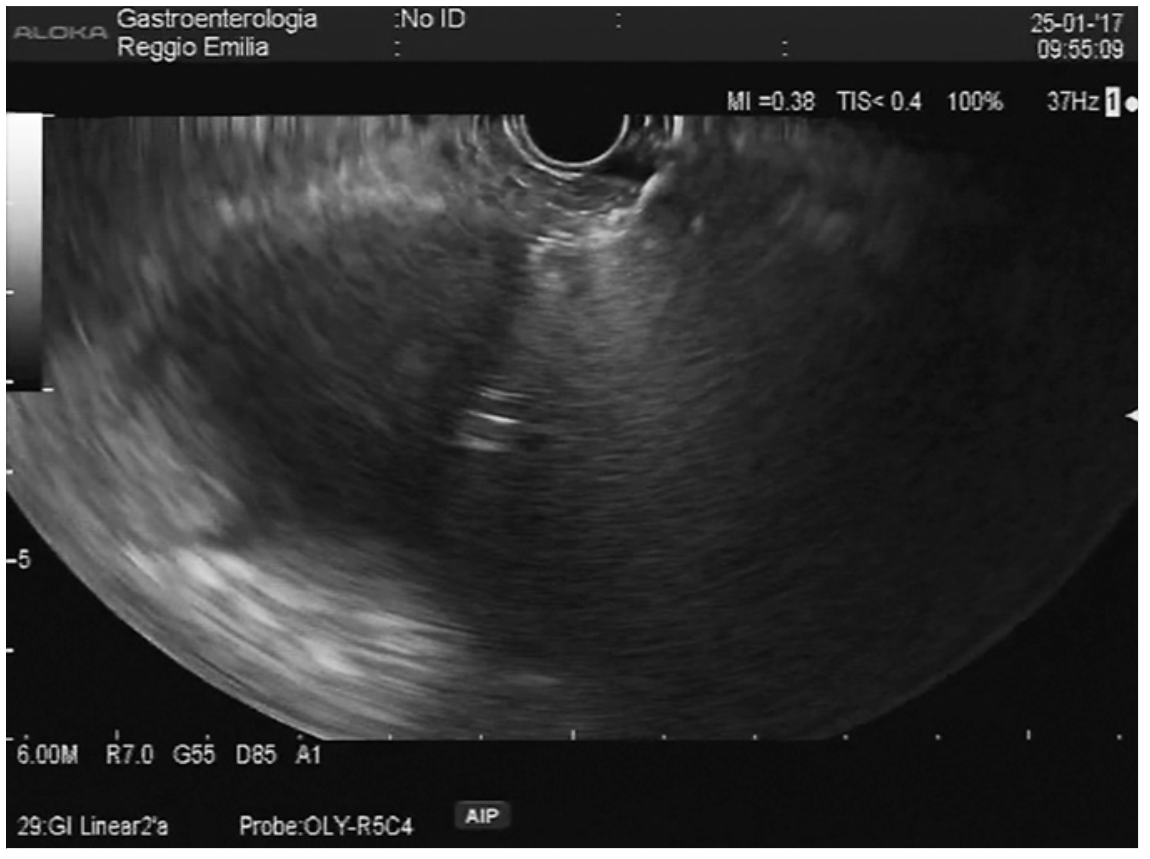

-Fig. 2 The metallic lumen-apposing metal stent (LAMS) stent deployed between gallbladder and jejunum.

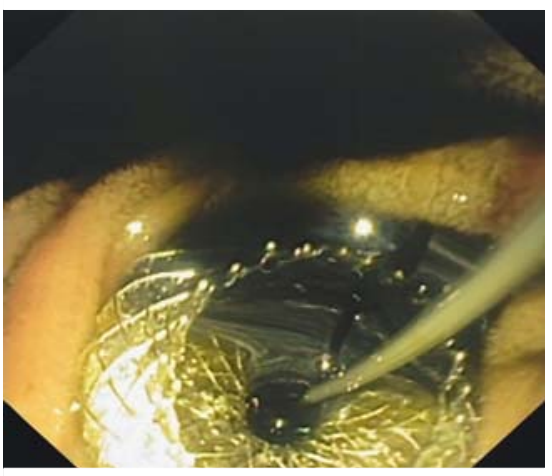

Fig. 3 Biliary drainage of the gallbladder via the jejunal lumen.

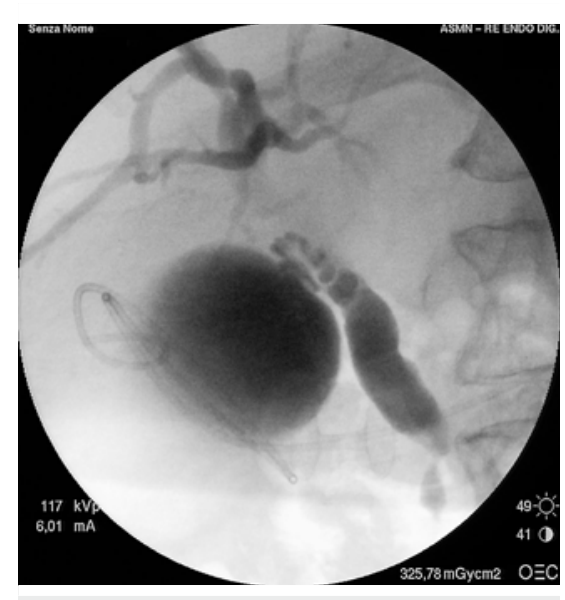

Fig. 4 Radiological image of the metallic stent with the nasobiliary drainage from the gallbladder
Corresponding author

\section{Paolo Cecinato, MD}

Unit of Gastroenterology and Digestive Endoscopy, Arcispedale Santa Maria NuovaIRCCS, Reggio Emilia, Italy

Phone: +39-0522-295941

paolo.cecinato@asmn.re.it

\section{References}

[1] Dollhopf M, Larghi A, Will U et al. EUSguided gallbladder drainage in patients with acute cholecystitis and high surgical risk using an electrocautery-enhanced lumen-apposing metal stent device. Gastrointest Endosc 2017. DOI: 10.1016/j. gie.2017.02.027

[2] Barbera C, Grande G, Alberghina N et al. Single-step endoscopic ultrasound-guided fluoroless gallbladder drainage using the Axios lumen-apposing metal stent. Endoscopy 2016; 48 (Suppl. 01): E25

\section{Bibliography}

DOI https://doi.org/10.1055/s-0043-113555

Published online: 29.6.2017

Endoscopy 2017; 49: E215-E216

(c) Georg Thieme Verlag KG

Stuttgart · New York

ISSN 0013-726X cal risk candidates $[1,2]$. Our case shov the feasibility of this technique also for obtaining palliative biliary endoscopic drainage when other routes are precluded.

Endoscopy_UCTN_Code_TTT_1AS_2AD

Competing interests

None

The Authors

Paolo Cecinato, Maurizio Cavina, Giuliana Sereni, Francesco Decembrino, Veronica Iori, Cristiana Tioli, Romano Sassatelli Unit of Gastroenterology and Digestive Endoscopy, Arcispedale Santa Maria NuovaIRCCS, Reggio Emilia, Italy https:/|eref.thieme.de/e-videos

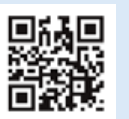

Endoscopy E-Videos is a free access online section, reporting on interesting cases and new techniques in gastroenterological quality video and all contributions are freely accessible online.

This section has its own submission website at

https://mc.manuscriptcentral.com/e-videos

\section{ENDOSCOPY E-VIDEOS} endoscopy. All papers include a high 